\title{
5-(2-18 F-Fluoroethoxy)-L-Tryptophan as a Substrate of System L Transport for Tumor Imaging by PET
}

\author{
Stefanie D. Krämer ${ }^{1}$, Linjing Mu², Adrienne Müller ${ }^{1}$, Claudia Keller ${ }^{1}$, Olga F. Kuznetsova ${ }^{1,3}$, Christian Schweinsberg ${ }^{2}$, \\ Dominic Franck ${ }^{1}$, Cristina Müller ${ }^{4}$, Tobias L. Ross ${ }^{1}$, Roger Schibli ${ }^{1,4}$, and Simon M. Ametamey ${ }^{1}$ \\ ${ }^{1}$ Center for Radiopharmaceutical Sciences ETH-PSI-USZ, Institute of Pharmaceutical Sciences ETH, Zurich, Switzerland; ${ }^{2}$ Center \\ for Radiopharmaceutical Sciences ETH-PSI-USZ, Department of Nuclear Medicine, University Hospital Zurich, Zurich, Switzerland; \\ ${ }^{3}$ N.P. Bechtereva Institute of Human Brain RAS, Russian Academy of Science, St. Petersburg, Russia; and ${ }^{4}$ Center for \\ Radiopharmaceutical Sciences ETH-PSI-USZ, Paul Scherrer Institute, Villigen, Switzerland
}

Large neutral L-amino acids are substrates of system $L$ amino acid transporters. The level of one of these, LAT1, is increased in many tumors. Aromatic L-amino acids may also be substrates of aromatic L-amino acid decarboxylase (AADC), the level of which is enhanced in endocrine tumors. Increased amino acid uptake and subsequent decarboxylation result in the intracellular accumulation of the amino acid and its decarboxylation product. ${ }^{18} \mathrm{~F}$ - and ${ }^{11} \mathrm{C}$-labeled neutral aromatic amino acids, such as L-3,4dihydroxy-6- ${ }^{18} \mathrm{~F}$-fluorophenylalanine $\left({ }^{18} \mathrm{~F}\right.$-FDOPA) and 5-hydroxy$\mathrm{L}-\left[\beta-{ }^{11} \mathrm{C}\right]$ tryptophan, are thus successfully used in PET to image endocrine tumors. However, 5-hydroxy-L- $\left[\beta-{ }^{11} \mathrm{C}\right]$ tryptophan has a relatively short physical half-life $(20 \mathrm{~min})$. In this work, we evaluated the in vitro and in vivo characteristics of the ${ }^{18} \mathrm{~F}$-labeled tryptophan analog 5-(2-18 F-fluoroethoxy)-L-tryptophan $\left({ }^{18} \mathrm{~F}-\right.$ L-FEHTP) as a PET probe for tumor imaging. Methods: ${ }^{18} \mathrm{~F}-\mathrm{L}-$ FEHTP was synthesized by no-carrier-added ${ }^{18} \mathrm{~F}$ fluorination of 5-hydroxy-L-tryptophan. In vitro cell uptake and efflux of ${ }^{18} \mathrm{~F}-\mathrm{L}-\mathrm{FEHTP}$ and ${ }^{18} \mathrm{~F}-\mathrm{FDOPA}$ were studied with $\mathrm{NCl}-\mathrm{H} 69$ endocrine small cell lung cancer cells, PC-3 pseudoendocrine prostate cancer cells, and MDA-MB-231 exocrine breast cancer cells. Small-animal PET was performed with the respective xenograft-bearing mice. Tissues were analyzed for potential metabolites. Results: ${ }^{18} \mathrm{~F}-\mathrm{L}-\mathrm{FEHTP}$ specific activity and radiochemical purity were $50-150 \mathrm{GBq} / \mu \mathrm{mol}$ and greater than $95 \%$, respectively. In vitro cell uptake of ${ }^{18} \mathrm{~F}-\mathrm{L}-\mathrm{FEHTP}$ was between $48 \%$ and $113 \%$ of added radioactivity per milligram of protein within $60 \mathrm{~min}$ at $37^{\circ} \mathrm{C}$ and was blocked by greater than $95 \%$ in all tested cell lines by the LAT1/2 inhibitor 2-amino-2-norboranecarboxylic acid. ${ }^{18}$ F-FDOPA uptake ranged from $26 \%$ to $53 \% / \mathrm{mg}$. PET studies revealed similar xenograft-to-reference tissue ratios for ${ }^{18} \mathrm{~F}-\mathrm{L}-\mathrm{FEHTP}$ and ${ }^{18}$ F-FDOPA at 30-45 min after injection. In contrast to the ${ }^{18} \mathrm{~F}-\mathrm{FDOPA}$ PET results, pretreatment with the AADC inhibitor S-carbidopa did not affect the ${ }^{18} \mathrm{~F}$-L-FEHTP PET results. No decarboxylation products of ${ }^{18} \mathrm{~F}-\mathrm{L}-\mathrm{FEHTP}$ were detected in the xenograft homogenates. Conclusion: ${ }^{18} \mathrm{~F}-\mathrm{L}-\mathrm{FEHTP}$ accumulates in endocrine and nonendocrine tumor models via LAT1 transport but is not decarboxylated by AADC. ${ }^{18} \mathrm{~F}-\mathrm{L}-$

Received Aug. 8, 2011; revision accepted Oct. 25, 2011.

For correspondence contact: Stefanie D. Krämer, Center for Radiopharmaceutical Sciences ETH-PSI-USZ, Institute of Pharmaceutical Sciences, Wolfgang-Pauli-Strasse 10, CH-8093 Zurich, Switzerland.

E-mail: stefanie.kraemer@pharma.ethz.ch

Published online Feb. 13, 2012.

COPYRIGHT @ 2012 by the Society of Nuclear Medicine, Inc.
FEHTP may thus serve as a PET probe for tumor imaging and quantification of tumor LAT1 activity. These findings are of interest in view of the ongoing evaluation of LAT1 substrates and inhibitors for cancer therapy.

Key Words: PET; tumor imaging; LAT; SLC7A; tryptophan

J Nucl Med 2012; 53:434-442

DOI: 10.2967/jnumed.111.096289

$\mathbf{M}$ ost malignant lesions have an increased demand for amino acids. This property makes ${ }^{18} \mathrm{~F}$ - and ${ }^{11} \mathrm{C}$-labeled $\alpha$-amino acids good candidates for tumor imaging by PET. Unlike ${ }^{18} \mathrm{~F}-\mathrm{FDG}$, the current gold standard for cancer imaging by PET, amino acids do not generally accumulate in the healthy brain or inflamed tissues. Amino acid-based PET probes thus provide good tumor-to-background ratios in the brain and allow differentiation between tumors and inflammation. Their accumulation in tumors is a consequence of increased amino acid uptake by cancer cells. In particular, the level of the heterodimer transport system for large neutral amino acids, LAT1/4F2hc (SLC7A5/SLC3A2; LAT1), is increased in many types of human tumors and may correlate with the malignancy of the lesion (1). The system $\mathrm{L}$ amino acid transporter (LAT) substrates L-[methyl- $\left.{ }^{11} \mathrm{C}\right]$ methionine and $O-\left(2-{ }^{18} \mathrm{~F}-\right.$ fluoroethyl $)-\mathrm{L}-$ tyrosine $\left({ }^{18} \mathrm{~F}-\mathrm{FET}\right)$ are used for brain tumor imaging $(1,2)$.

The aromatic L-amino acids L-3,4-dihydroxyphenylalanine, L-tryptophan, and 5-hydroxy-L-tryptophan are substrates not only of LAT1 but also of aromatic L-amino acid decarboxylase (AADC), the level of which is enhanced in tumor cells with an endocrine character (3). Decarboxylation of those amino acids produces biogenic amines, which can subsequently be trapped in secretory vesicles. The combination of amino acid uptake and decarboxylation has been designated the APUD (amine precursor uptake and decarboxylation) concept (4). The PET probes L-3,4-dihydroxy-6- ${ }^{18}$ F-fluorophenylalanine $\left({ }^{18} \mathrm{~F}-\mathrm{FDOPA}\right)$ and 5 -hydroxy-L- $\left[\beta-{ }^{11} \mathrm{C}\right]$ tryptophan $\left({ }^{11} \mathrm{C}-5 \mathrm{HTP}\right)$ accumulate according to the APUD concept in endocrine tumors $(1,5)$. 
We aimed at synthesizing and evaluating an ${ }^{18} \mathrm{~F}$-labeled alternative to ${ }^{11} \mathrm{C}$-5HTP for tumor imaging by PET because the longer physical half-life of ${ }^{18} \mathrm{~F}(110 \mathrm{~min})$ has several advantages over the 20 -min half-life of ${ }^{11} \mathrm{C}(6)$. We hypothesized that $5-\left(2-{ }^{18} \mathrm{~F}\right.$-fluoroethoxy)-L-tryptophan $\left({ }^{18} \mathrm{~F}-\mathrm{L}\right.$-FEHTP $)$ (Fig. 1) is a substrate of LATs and possibly of AADC, similar to ${ }^{11} \mathrm{C}-5 \mathrm{HTP}$, and therefore would be a good PET probe for imaging endocrine tumors and possibly other tumors. During our evaluation of ${ }^{18} \mathrm{~F}-\mathrm{L}-\mathrm{FEHTP}$, the synthesis of ${ }^{18} \mathrm{~F}-\mathrm{L}-\mathrm{FEHTP}$ and the first PET images and biodistribution results obtained with ${ }^{18} \mathrm{~F}-\mathrm{L}-\mathrm{FEHTP}$ in S180 fibrosarcomabearing mice were published by $\mathrm{Li}$ et al. (7).

In this work, we describe the synthesis of ${ }^{18} \mathrm{~F}$-L-FEHTP and compare its biochemical and pharmacologic characteristics in cell cultures and in small-animal PET with those of ${ }^{18} \mathrm{~F}$-FDOPA. For the in vitro and in vivo evaluations, we chose an endocrine tumor model, the small cell lung cancer cell line NCI-H69 with high AADC activity (8); the so-called "pseudoendocrine" prostate cancer cell line PC-3, which has been shown to express AADC at the messenger RNA level (9); and exocrine breast cancer cell line MDA-MB-231, which displays no AADC activity. LAT1 expression has been shown to occur in all 3 cell lines (10-12).

\section{MATERIALS AND METHODS}

\section{Radiosynthesis}

${ }^{18} \mathrm{~F}-\mathrm{L}$-FEHTP was prepared with a 2 -step radiolabeling approach similar to that described recently (7) and as depicted in Figure 1. The disodium salt of 5-hydroxy-L-tryptophan was prepared by reacting 5-hydroxy-L-tryptophan with 2 equivalent sodium methoxide $(0.5 \mathrm{~N})$ in dry methanol at room temperature. No-carrier-added ${ }^{18} \mathrm{~F}$-fluoride was produced via the ${ }^{18} \mathrm{O}(\mathrm{p}, \mathrm{n}){ }^{18} \mathrm{~F}$ nuclear reaction by irradiation of enriched ${ }^{18} \mathrm{O}$-water in a cyclotron (Cyclone 18/9; IBA). ${ }^{18} \mathrm{~F}$-fluoride was immobilized on an anion-exchange cartridge (QMA Light; Waters) preconditioned with $\mathrm{K}_{2} \mathrm{CO}_{3}(5 \mathrm{~mL}, 0.5 \mathrm{M})$ and then $5-10 \mathrm{~mL}$ of water. The activity was eluted with tetrabutylammonium hydroxide $(0.6 \mathrm{~mL}, 0.18 \mathrm{mM})$ and dried under vacuum with a stream of nitrogen at $110^{\circ} \mathrm{C}$. Azeotropic drying was repeated 3 times with $1 \mathrm{~mL}$ of acetonitrile each time. To the dried ${ }^{18} \mathrm{~F}$-fluoride complex (typically $20 \mathrm{GBq}$ ), ethylene glycol ditosylate (5-6 mg in $0.9 \mathrm{~mL}$ of $\mathrm{CH}_{3} \mathrm{CN}$ ) was added, and the mixture was heated at $105^{\circ} \mathrm{C}$ for $6 \mathrm{~min}$. The reaction mixture was cooled, diluted with $35 \%$ ethanol in water $(10 \mathrm{~mL})$, and passed through a LiChrolute EN cartridge (Merck). The ${ }^{18} \mathrm{~F}$-labeled product was eluted with dimethyl sulfoxide (DMSO; $0.8-0.9 \mathrm{~mL}$ ) to the second reactor, which had been preloaded with 5-hydroxy-L-tryptophan disodium salt (5-10 $\mathrm{mg})$ in a mixture of DMSO $(0.20 \mathrm{~mL})$ and water $(0.15 \mathrm{~mL})$. The reaction mixture was heated at $120^{\circ} \mathrm{C}$ for 9 min. After cooling, the reaction mixture was diluted with water $(1.8-2.0 \mathrm{~mL})$ and purified by semipreparative high-performance liquid chromatography (HPLC) (Supplemental Material) (supplemental materials are available online only at http://jnm.snmjournals.org). The ${ }^{18} \mathrm{~F}$-L-FEHTP product was collected at about $14 \mathrm{~min}$ and neutralized with sodium hydrogen carbonate $(8.4 \%)$. The solution was passed through a sterile filter and used for in vitro and in vivo studies.

${ }^{18} \mathrm{~F}$-DL-FEHTP was produced by the same procedure but with the racemic 5-hydroxy-tryptophan disodium salt.

${ }^{18} \mathrm{~F}$-FDOPA was obtained at the University Hospital Zurich from routine production for clinical use (13). The specific activity was $9-120 \mathrm{GBq} / \mathrm{mmol}$ at the end of synthesis.

\section{In Vitro Cell Studies}

PC-3, NCI-H69, and MDA-MB-231 cells were purchased from the German Collection of Microorganisms and Cell Cultures, Cell Lines Service, and the American Type Culture Collection, respectively. Cells were grown to subconfluence in 48-well plates (Costar; Corning) or 5-mL plastic tubes (for NCI-H69). Cells were washed and incubated for $1 \mathrm{~h}$ at $37^{\circ} \mathrm{C}$ with Earle balanced salt solution containing $\mathrm{Ca}^{2+}$ and $\mathrm{Mg}^{2+}$ (EBSS; Invitrogen). The irreversible monoamine oxidase A and B inhibitors clorgyline (Sigma) and pargyline (Acros Organics), respectively, and-if indicatedthe LAT inhibitor 2-amino-2-norboranecarboxylic acid $(\mathrm{BCH})$ were added at final concentrations of $0.1,0.1$, and $10 \mathrm{mM}$, respectively. At time zero, about $20 \mathrm{kBq}$ of ${ }^{18} \mathrm{~F}-\mathrm{L}-\mathrm{FEHTP}$ or ${ }^{18} \mathrm{~F}-\mathrm{FDOPA}$ were added, and the cells were incubated at $37^{\circ} \mathrm{C}$ or on ice. The final tracer concentrations were $0.3-4 \mathrm{nM}{ }^{18} \mathrm{~F}-\mathrm{L}-$ FEHTP and $0.3-4 \mu \mathrm{M}{ }^{18}$ F-FDOPA, that is, less than typical Michaelis-Menten constants $\mathrm{K}_{\mathrm{M}}$ values for LAT1 and AADC (14). Total uptake was less than $15 \%$ of the added tracer after 1 h. At various time points, the cells were washed twice with ice-cold EBSS, and adherent cells were detached with trypsin-ethylenediaminetetraacetic acid (Invitrogen). All cells were transferred to Eppendorf tubes, and the radioactivity was quantified in a $\gamma$-counter (Wizard 1480; PerkinElmer). To inhibit AADC, we added $80 \mu \mathrm{M}$ $S$-carbidopa (Santa Cruz Biotechnology) in DMSO-100 mM phosphate-buffered saline $30 \mathrm{~min}$ before tracer addition. The final DMSO concentration was $0.3 \%$. Cell viability was $80 \%-90 \%$ after $60 \mathrm{~min}$ for all conditions, as tested with trypan blue staining.

For efflux assays, cells were preincubated for $1 \mathrm{~h}$ as described earlier, and then the cultures were washed twice with ice-cold EBSS and incubated with EBSS or EBSS containing $0.8 \mathrm{mM}$ L-leucine (time zero). At various time points, the cells were washed twice with ice-cold EBSS, detached as described earlier,

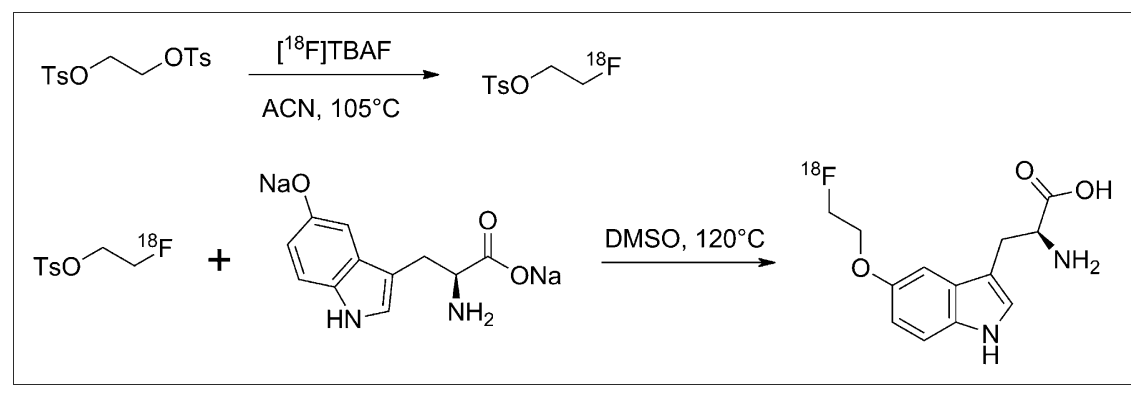

FIGURE 1. Radiosynthesis scheme for generation of ${ }^{18} \mathrm{~F}-\mathrm{L}-\mathrm{FEHTP}$. ACN = acetonitrile; TBAF = tetra-n-butylammonium fluoride; Ts = tosyl. 
and analyzed in the $\gamma$-counter. Protein was quantified with the DC Protein Assay (Bio-Rad) after cell lysis with 2\% sodium dodecyl sulfate. Bovine serum albumin was used for calibration.

\section{In Vivo PET Experiments}

Animal care and experiments were conducted in accordance with Swiss Animal Welfare legislation and were approved by the Veterinary Office of Canton Zurich, Zurich, Switzerland. Fiveweek-old female NMRI nude and BALB/c mice were supplied by Charles River. They were allowed free access to water and food.

Six-week-old mice were inoculated subcutaneously in the right shoulder with $2 \times 10^{6}$ PC-3 or MDA-MB-231 cells in $100 \mu \mathrm{L}$ of Matrigel (BD Biosciences) or $5 \times 10^{6}$ NCI-H69 cells in $100 \mu \mathrm{L}$ of phosphate-buffered saline with $\mathrm{Ca}^{2+}$ and $\mathrm{Mg}^{2+}$ (Invitrogen). At 3-5 wk after inoculation, when the tumor volumes reached $0.2-1.5 \mathrm{~cm}^{3}$, the mice were injected in a tail vein with $3.5-18 \mathrm{MBq}$ of ${ }^{18} \mathrm{~F}-\mathrm{L}-$ FEHTP or ${ }^{18} \mathrm{~F}$-FDOPA. For experiments with AADC inhibition, mice were injected intraperitoneally with $S$-carbidopa at $25 \mathrm{mg} / \mathrm{kg}$ $60 \mathrm{~min}$ before tracer injection. For transport competition experiments, mice were injected intraperitoneally with L-tryptophan at $25 \mathrm{mg} / \mathrm{kg} 10 \mathrm{~min}$ before tracer injection. Anesthesia with $2 \%-3 \%$ isoflurane in oxygen-air was initiated 10 min before the PET scan, and animals were monitored as described previously (15).

PET scans were performed with a VISTA eXplore small-animal PET/CT camera (GE Healthcare) in list mode for dynamic analysis or static mode for whole-body scans ( 2 bed positions) (16). Static scans with 2 bed positions were started with the anterior body part containing the tumor $30 \mathrm{~min}$ after tracer injection. The complete 2 bed position scans lasted $30 \mathrm{~min}$ (15 min per bed position). Data were reconstructed with the 2-dimensional ordered-subsets expectation maximization protocol and analyzed with PMOD Version 3.2 software (PMOD Technologies Ltd.). A region of interest for the xenograft, a reference region of equal shape and volume on the contralateral side, and a region of interest for the brain were drawn in PMOD on the basis of the PET images. Tissue radioactivity was expressed as the standardized uptake value (SUV), that is, the decay-corrected radioactivity per cubic centimeter divided by the injected radioactivity dose per gram of body weight.

\section{Ex Vivo Biodistribution, Metabolite Studies, and In Vitro Plasma Albumin Binding}

After the PET scans, mice were sacrificed by decapitation under isoflurane anesthesia, and tissues were removed, weighed, and analyzed in the $\gamma$-counter. The accumulated radioactivity per gram of tissue was calculated as the decay-corrected radioactivity per gram of tissue divided by the injected radioactivity dose per gram of body weight.

For ex vivo metabolite studies, $14-32 \mathrm{MBq}$ of ${ }^{18} \mathrm{~F}-\mathrm{L}-\mathrm{FEHTP}$ or ${ }^{18} \mathrm{~F}-\mathrm{FDOPA}$ were injected via a lateral tail vein into xenograft-bearing 9- to 12-wk-old NMRI nude mice. Blood samples were withdrawn via the opposite tail vein, and animals were sacrificed by decapitation under isoflurane anesthesia at various time points. Xenografts were excised and homogenized in equal volumes of phosphate-buffered saline (Invitrogen) with a Polytron (Kinematica, Inc.). Proteins in the xenograft homogenates, plasma, and urine were precipitated with equal volumes of ice-cold acetonitrile and centrifugation. Supernatants of the xenograft homogenates were extracted again, and all supernatants were filtered and analyzed by reversed-phase thin-layer chromatography and ultra-performance liquid chromatography (Supplemental Material). Serum albumin binding was determined by equilibrium dialysis as described in the Supplemental Material.

\section{RESULTS}

\section{Radiosynthesis of ${ }^{18} \mathrm{~F}-\mathrm{L}-\mathrm{FEHTP}$ and ${ }^{18} \mathrm{~F}-\mathrm{DL}-\mathrm{FEHTP}$}

Chiral HPLC analysis demonstrated that an L-enantiomeric pure product was obtained when an L-enantiomeric pure precursor was used for radiolabeling. In a typical experiment, a radiochemical yield of about $23 \%$ (decay corrected, corresponding to $15 \%$ not decay corrected) was achieved with a radiochemical purity of greater than $95 \%$. The specific activities were in the range of $50-150 \mathrm{GBq} / \mu \mathrm{mol}$ at the end of synthesis. When 5-hydroxy-DL-tryptophan disodium salt was used as the precursor, similar radiochemical yield and radiochemical purity were obtained.

\section{In Vitro Cell Uptake and Efflux Studies}

Figure 2 shows the rapid influx of ${ }^{18} \mathrm{~F}-\mathrm{L}-\mathrm{FEHTP}$ and ${ }^{18} \mathrm{~F}$ FDOPA into NCI-H69 endocrine cells at $37^{\circ} \mathrm{C}$ and $4{ }^{\circ} \mathrm{C}$, reaching between $37 \%$ and $52 \%$ of the total added radioactivity per milligram of protein within $5 \mathrm{~min}$. After the fast initial uptake, ${ }^{18} \mathrm{~F}$-L-FEHTP radioactivity increased steadily, whereas ${ }^{18} \mathrm{~F}$-FDOPA radioactivity decreased at $37^{\circ} \mathrm{C}$ but not at $4^{\circ} \mathrm{C}$.

When no amino acids were added to the incubation buffer, the efflux of ${ }^{18} \mathrm{~F}$-L-FEHTP was slow compared with the uptake at $37^{\circ} \mathrm{C}$ and was negligible at $4^{\circ} \mathrm{C}$ (Fig. 2B). The

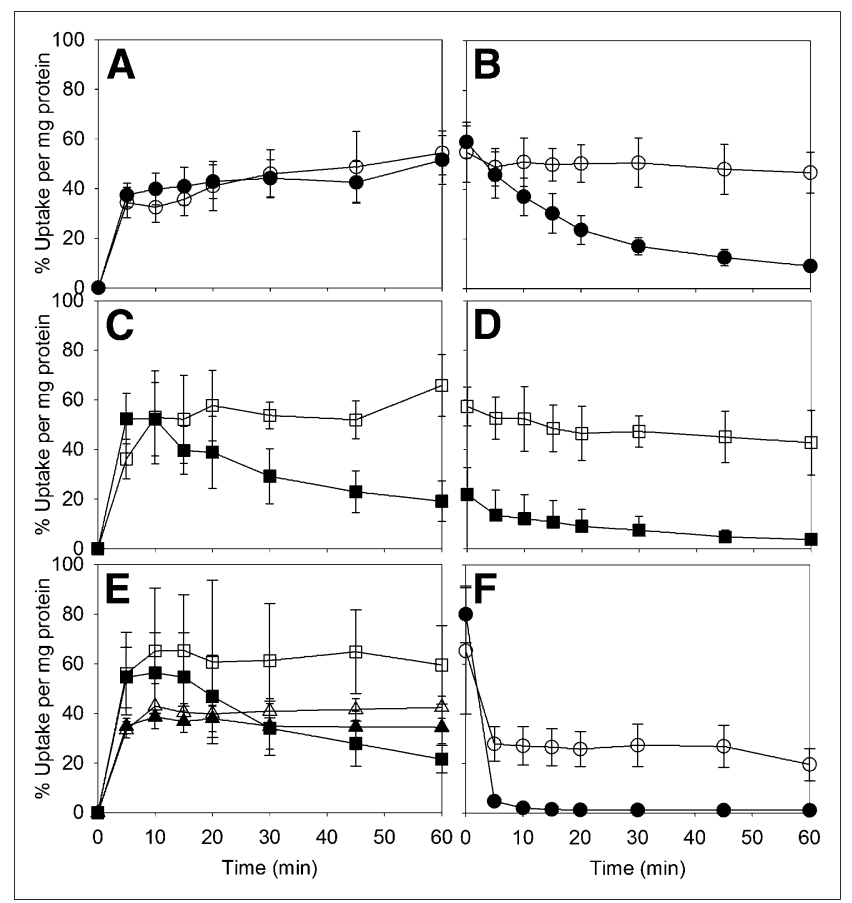

FIGURE 2. (A-D) Uptake (A and $C$ ) and efflux after $60 \mathrm{~min}$ of uptake (B and D) of ${ }^{18} \mathrm{~F}-\mathrm{L}-\mathrm{FEHTP}(\mathrm{A}$ and $\mathrm{B})$ and ${ }^{18} \mathrm{~F}-\mathrm{FDOPA}(\mathrm{C}$ and $\mathrm{D})$ in $\mathrm{NCl}-\mathrm{H} 69$ cell cultures at $37^{\circ} \mathrm{C}(\mathbf{a}$ and $\square)$ and $4^{\circ} \mathrm{C}(\bigcirc$ and $\square$ ). (E) ${ }^{18} \mathrm{~F}$-FDOPA uptake in presence of $80 \mu \mathrm{M}$ S-carbidopa ( $\boldsymbol{\Delta}$ and $\triangle$ ) and $0.3 \%$ DMSO as control ( $\boldsymbol{\square}$ and $\square$ ) at $37^{\circ} \mathrm{C}$ ( $\boldsymbol{\Delta}$ and $\boldsymbol{\square}$ ) and $4^{\circ} \mathrm{C}(\triangle$ and $\square)$. (F) ${ }^{18} \mathrm{~F}-\mathrm{L}-\mathrm{FEHTP}$ efflux in presence of $0.8 \mathrm{mM} \mathrm{L}-$ leucine in incubation buffer at $37^{\circ} \mathrm{C}(\bullet)$ and $4^{\circ} \mathrm{C}(\bigcirc)$. Symbols represent averages from 3 independent experiments each (except for 2 independent experiments with L-leucine). Error bars show SDs, except for experiments with L-leucine, for which error bars indicate values from 2 independent experiments. 
release of ${ }^{18} \mathrm{~F}$-FDOPA or its metabolites continued as observed during uptake at $37^{\circ} \mathrm{C}$ and was negligible at $4^{\circ} \mathrm{C}$ (Fig. 2D). The decrease in radioactivity after the initial fast uptake of ${ }^{18}$ F-FDOPA was almost abolished in the presence of $80 \mu \mathrm{M} S$-carbidopa (Fig. 2E). At this concentration, intracellular AADC is partially inhibited without a significant loss of viability of endocrine tumor cells $(5,17,18)$. Figure $2 \mathrm{~F}$ shows the rapid efflux of ${ }^{18} \mathrm{~F}-\mathrm{L}-\mathrm{FEHTP}$ at $37^{\circ} \mathrm{C}$ and $4{ }^{\circ} \mathrm{C}$ after the addition of $0.8 \mathrm{mM}$ L-leucine, a LAT1 substrate.

The accumulation (average $\pm \mathrm{SD}$ ) of ${ }^{18} \mathrm{~F}$-L-FEHTP and ${ }^{18} \mathrm{~F}-\mathrm{FDOPA}$ in PC-3 cells reached $113 \% \pm 19 \% / \mathrm{mg}$ and $53 \% \pm 15 \% / \mathrm{mg}$, respectively, of added radioactivity at $37^{\circ}$ $\mathrm{C}$ and 60 min (Fig. 3). Efflux was negligible at $4^{\circ} \mathrm{C}$ but was significant at $37^{\circ} \mathrm{C}$. As observed for NCI-H69 cells, the addition of $0.8 \mathrm{mM}$ L-leucine resulted in the rapid efflux of ${ }^{18} \mathrm{~F}-\mathrm{L}$-FEHTP and ${ }^{18} \mathrm{~F}$-FDOPA within $5 \mathrm{~min}$. The uptake of racemic ${ }^{18} \mathrm{~F}$-DL-FEHTP was between $50 \%$ and $70 \%$ of that of ${ }^{18} \mathrm{~F}-\mathrm{L}-\mathrm{FEHTP}$, indicating a lower level of uptake of the D-isomer than of the L-isomer (Fig. 3A).

Figure 4 shows the accumulation of ${ }^{18}$ F-labeled amino acids in MDA-MB-231 exocrine cells. ${ }^{18} \mathrm{~F}-\mathrm{L}$-FEHTP and ${ }^{18} \mathrm{~F}$-FDOPA uptake reached $48 \% \pm 3 \% / \mathrm{mg}$ and $26 \% \pm$ $4 \% / \mathrm{mg}$, respectively, of added radioactivity after $60 \mathrm{~min}$ of incubation at $37^{\circ} \mathrm{C}$. Both amino acids also showed significant uptake at $4^{\circ} \mathrm{C}$. When no amino acids were added to the incubation buffer, both amino acids showed moderate efflux at $37^{\circ} \mathrm{C}$ and no significant net efflux at $4^{\circ} \mathrm{C}$.

The LAT competitive inhibitor BCH blocked ${ }^{18} \mathrm{~F}$-L-FEHTP uptake in all cell lines by greater than $95 \%$ at $10 \mathrm{mM}$. Block-

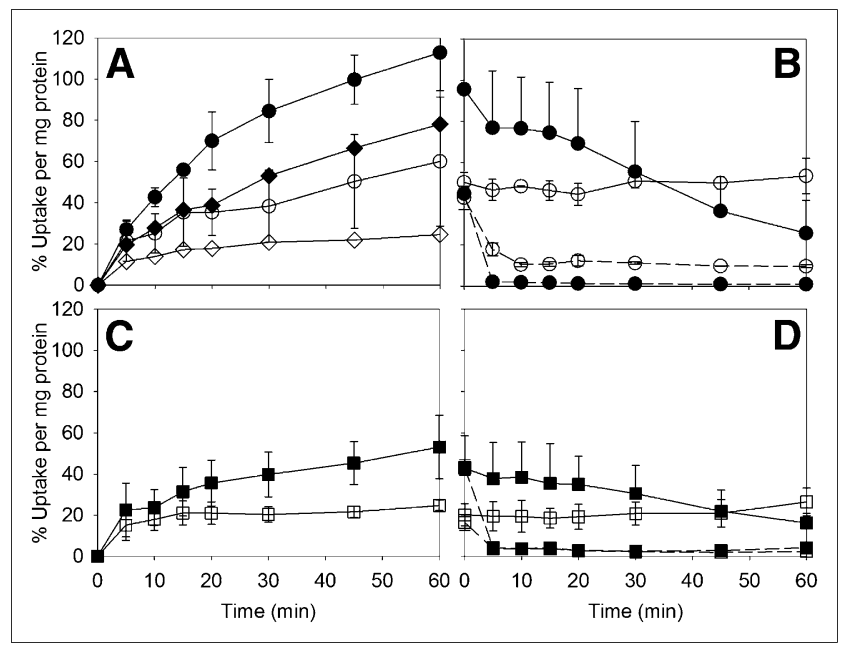

FIGURE 3. Uptake ( $A$ and $C$ ) and efflux (B and $D)$ in PC-3 cells of ${ }^{18} \mathrm{~F}-$ L-FEHTP ( $A$ and $B,-$ at $37^{\circ} \mathrm{C}$ and $\bigcirc$ at $4^{\circ} \mathrm{C}$ connected with solid lines), ${ }^{18} \mathrm{~F}$-DL-FEHTP (A, $\diamond$ at $37^{\circ} \mathrm{C}$ and $\diamond$ at $4^{\circ} \mathrm{C}$ ), and ${ }^{18} \mathrm{~F}-\mathrm{FDOPA}$ (C and D, $\mathbf{\square}$ at $37^{\circ} \mathrm{C}$ and $\bigcirc$ at $4^{\circ} \mathrm{C}$ connected with solid lines). Efflux of ${ }^{18} \mathrm{~F}-\mathrm{L}-\mathrm{FEHTP}$ (B) and ${ }^{18} \mathrm{~F}-\mathrm{FDOPA}(\mathrm{D})$ was also studied with $0.8 \mathrm{mM}$ L-leucine in incubation buffer (symbols connected with dashed lines). Symbols represent averages from 3 independent experiments each (except for 2 independent experiments with L-leucine and 1 experiment with ${ }^{18} \mathrm{~F}-\mathrm{DL}-$ FEHTP). Error bars show SDs, except for experiments with L-leucine, for which error bars indicate values from 2 independent experiments.

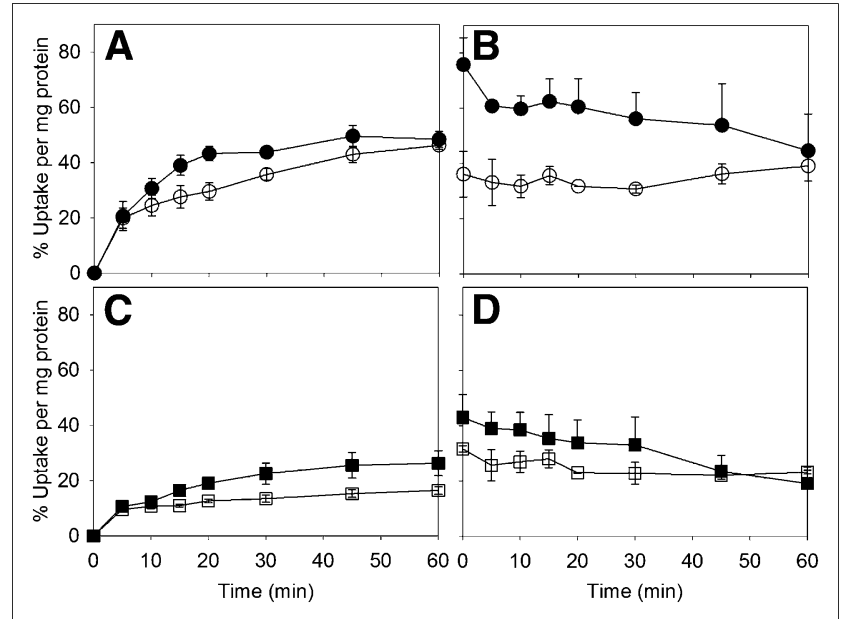

FIGURE 4. Uptake ( $A$ and $C$ ) and efflux (B and D) of ${ }^{18}$ F-L-FEHTP ( $A$ and $B$ ) and ${ }^{18} \mathrm{~F}-\mathrm{FDOPA}\left(\mathrm{C}\right.$ and $\mathrm{D}$ ) in MDA-MB-231 cells at $37^{\circ} \mathrm{C}$ ( $\bigcirc$ and $\square$ ) and $4^{\circ} \mathrm{C}(\bigcirc$ and $\square)$. Symbols and error bars represent averages and SDs from 3 independent experiments each.

ing was less efficient for ${ }^{18} \mathrm{~F}-\mathrm{FDOPA}$, with $13 \% \pm 6 \%$ and $10 \% \pm 6 \%$ residual uptake at $37^{\circ} \mathrm{C}$ in NCI-H69 cells and PC3 cells, respectively (Supplemental Material).

\section{In Vivo Metabolism}

${ }^{18}$ F-FDOPA and 5-hydroxy-L-tryptophan are decarboxylated in humans and laboratory animals (19). We found only radioactive metabolites and no ${ }^{18} \mathrm{~F}$-FDOPA in the blood, brain, and tumor 60 min after ${ }^{18}$ F-FDOPA administration (data not shown). In contrast, mainly parent ${ }^{18} \mathrm{~F}-\mathrm{L}-$ FEHTP was detected in the blood, brain, and xenografts 15 and $60 \mathrm{~min}$ after ${ }^{18} \mathrm{~F}-\mathrm{L}-\mathrm{FEHTP}$ administration. Some radioactive metabolites of unknown identity were detected in the urine, and traces were detected in the blood. The results of reversed-phase thin-layer chromatography of the tissue extracts are shown in Figure 5. The results were confirmed by ultra-performance liquid chromatography with 2 different mobile phases (data not shown).

\section{Small-Animal PET with Xenograft-Bearing Mice}

On the basis of the favorable uptake kinetics of ${ }^{18} \mathrm{~F}-\mathrm{L}-$ FEHTP in the cell experiments, we expected significant uptake into xenografts in vivo. Pilot dynamic PET scans with NMRI nude mice showed the accumulation of both ${ }^{18} \mathrm{~F}-\mathrm{L}-$ FEHTP and ${ }^{18} \mathrm{~F}-\mathrm{FDOPA}$ in PC-3 xenografts. The ${ }^{18} \mathrm{~F}-\mathrm{L}-$ FEHTP SUV ratios in the xenografts and reference tissues decreased with time between 30 and 150 min after injection. The ${ }^{18} \mathrm{~F}$-FDOPA SUV ratios did not decrease, in accordance with the APUD concept (Fig. 6). We chose the time window of 30-45 min after injection for static PET scans. No significant uptake of ${ }^{18} \mathrm{~F}-\mathrm{L}$-FEHTP into bone was observed, indicating that in vivo defluorination was negligible.

Figure 7A shows PET images (static) of NMRI nude mice bearing NCI-H69, PC-3, and MDA-MB-231 xenografts. ${ }^{18}$ F-FDOPA was administered after $S$-carbidopa preadministration. The levels of radioactivity accumulation in the xeno- 


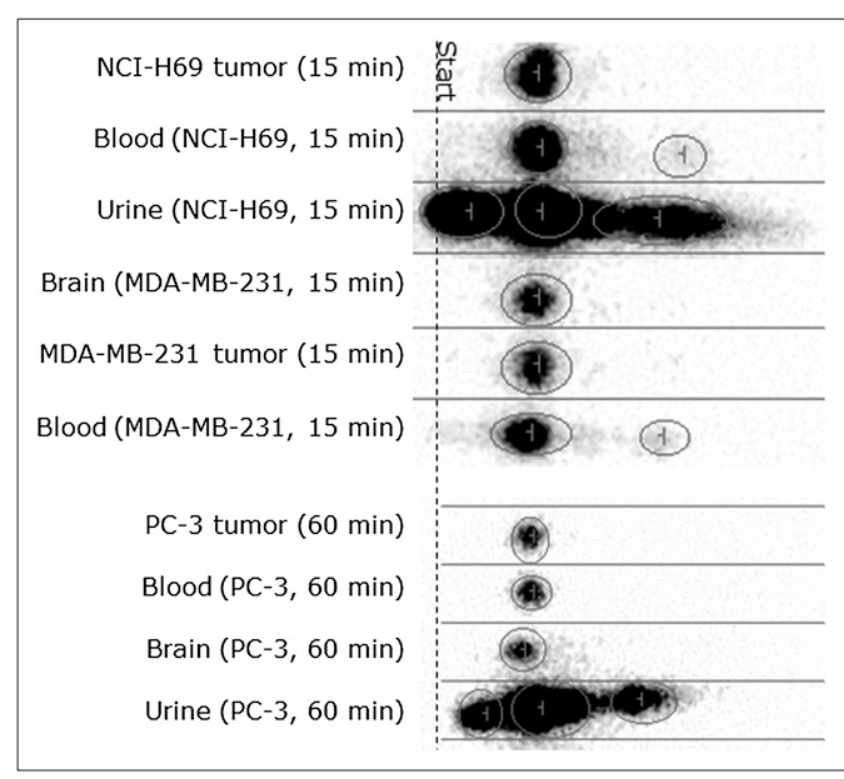

FIGURE 5. In vivo metabolism of ${ }^{18} \mathrm{~F}-\mathrm{L}-\mathrm{FEHTP} .{ }^{18} \mathrm{~F}-\mathrm{L}-\mathrm{FEHTP}(14$ $32 \mathrm{MBq}$ ) was injected into xenograft-bearing NMRI nude mice. Tissues were extracted and analyzed by reversed-phase thin-layer chromatography. ${ }^{18} \mathrm{~F}$-L-FEHTP reference sample had same retention time as main spot in all lanes. Minutes indicate time of sacrifice after ${ }^{18} \mathrm{~F}$-L-FEHTP injection. No metabolites were detected in xenografts, and only traces of metabolites were detected in blood.

grafts and reference regions were similar for the 2 tracers. Figures 7B and 7C show the respective SUVs and SUV ratios. The MDA-MB-231 xenografts had a large gelatinous core (Supplemental Material), resulting in relatively low levels of average tumor uptake of ${ }^{18} \mathrm{~F}$-L-FEHTP and ${ }^{18} \mathrm{~F}$-FDOPA. However, PET sectional reconstruction (Fig. 7A) showed tracer accumulation in the periphery of the MDA-MB-231 xenografts.

${ }^{18}$ F-DL-FEHTP was tested in a PC-3 xenograft-bearing mouse. The xenograft and reference tissue SUVs were about half those of ${ }^{18} \mathrm{~F}-\mathrm{L}-\mathrm{FEHTP}$, resulting in a similar xenograft-

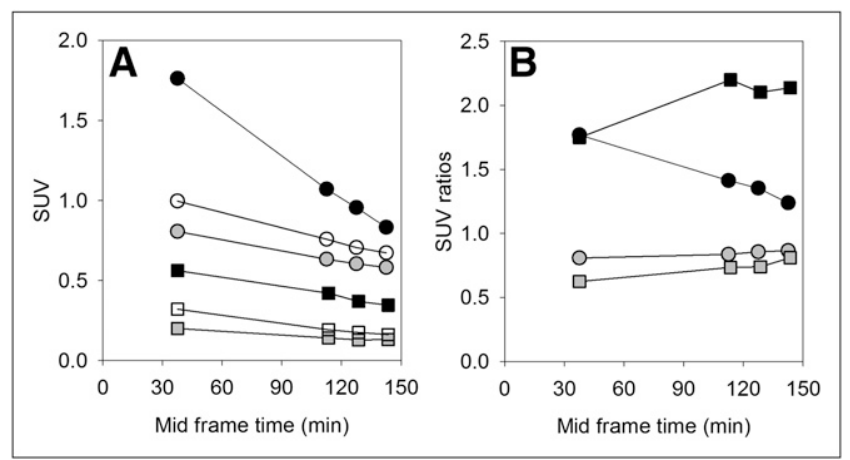

FIGURE 6. (A) Time-activity curves (SUVs) for ${ }^{18} \mathrm{~F}-\mathrm{L}-\mathrm{FEHTP}$ (circles) and ${ }^{18} \mathrm{~F}-\mathrm{FDOPA}$ (squares) in PC-3 xenografts (black), brain (gray), and reference tissue (no fill). (B) Ratios of PC-3 xenograft activity to reference tissue activity (black) and brain activity to reference tissue activity (gray) for ${ }^{18} \mathrm{~F}-\mathrm{L}-\mathrm{FEHTP}$ (circles) and ${ }^{18} \mathrm{~F}-\mathrm{FDOPA}$ (squares). Connected symbols represent time-activity curves from 1 mouse. ${ }^{18} \mathrm{~F}-\mathrm{FDOPA}$ was used without $S$-carbidopa. to-reference tissue SUV ratio as found with ${ }^{18} \mathrm{~F}$-L-FEHTP (data not shown).

Next, we investigated whether plasma L-tryptophan levels had an influence on ${ }^{18} \mathrm{~F}-\mathrm{L}$-FEHTP PET images. After the administration of tryptophan at $25 \mathrm{mg} / \mathrm{kg}$, the xenograft SUVs
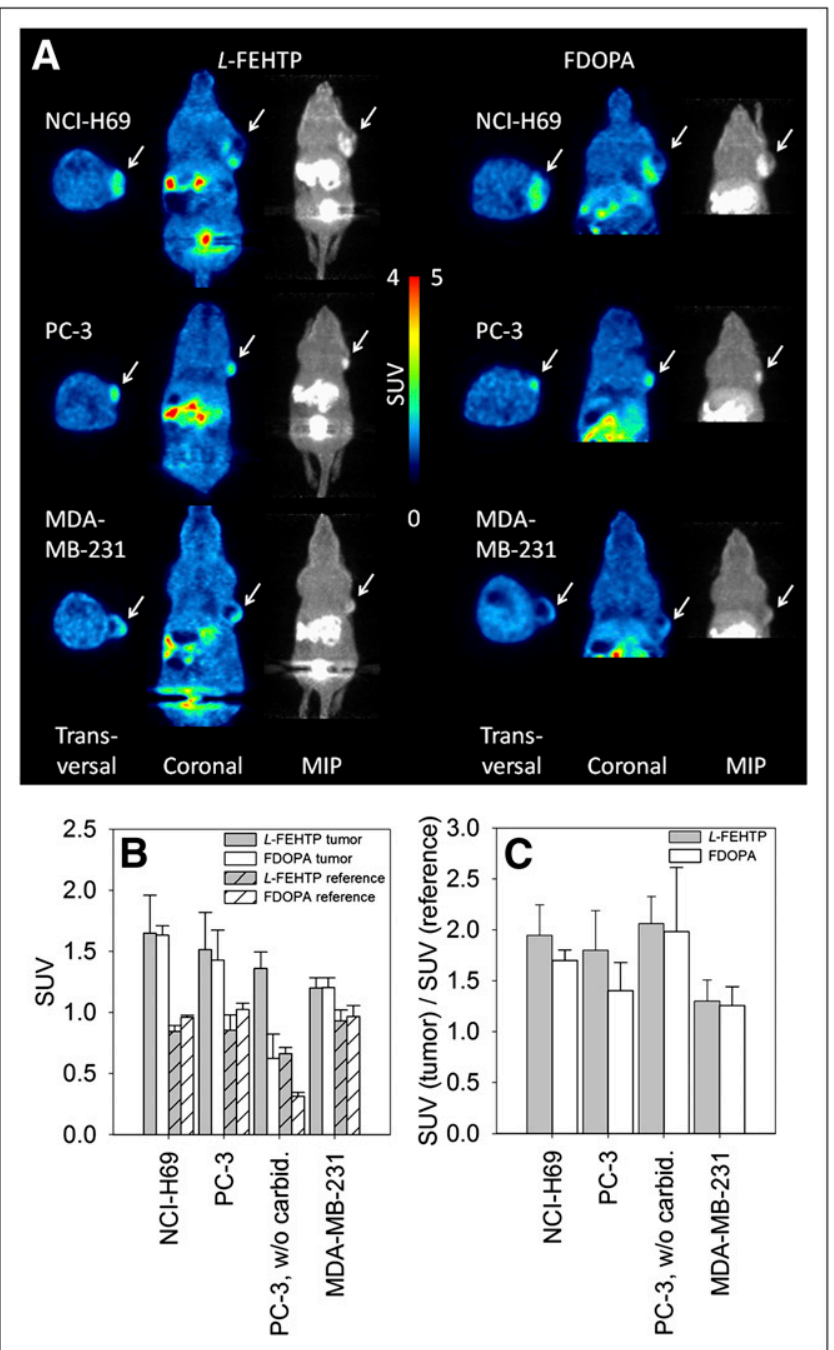

FIGURE 7. PET analysis of xenograft-bearing mice with ${ }^{18} \mathrm{~F}-\mathrm{L}-$ FEHTP and ${ }^{18} \mathrm{~F}-\mathrm{FDOPA}$. (A) Identical NCl-H69 (top row), PC-3 (middle row), and MDA-MB-231 (bottom row) xenograft-bearing NMRI nude mice were each scanned with ${ }^{18} \mathrm{~F}-\mathrm{L}-\mathrm{FEHTP}$ (left of scale bar) and ${ }^{18} \mathrm{~F}-$ FDOPA (right of scale bar). At $1 \mathrm{~h}$ before ${ }^{18} \mathrm{~F}$-FDOPA scans, S-carbidopa $(25 \mathrm{mg} / \mathrm{kg})$ was injected intraperitoneally. Shown are transversal and coronal sections (SUV color scale) and maximum-intensity projections (MIP, gray scale). Tumors are indicated by arrows. (B) SUVs of xenografts and reference regions after ${ }^{18} \mathrm{~F}-\mathrm{L}-\mathrm{FEHTP}$ and ${ }^{18} \mathrm{~F}-\mathrm{FDOPA}$ injections. PC-3, w/o carbid. = PC-3 xenograft-bearing BALB/c mice without $S$-carbidopa pretreatment (images not shown). (C) Ratios of xenograft SUVs to reference region SUVs for ${ }^{18} \mathrm{~F}-\mathrm{L}-\mathrm{FEHTP}$ and ${ }^{18} \mathrm{~F}-$ FDOPA. Data are averages and SDs from 3-7 animals each. There were no significant differences between ${ }^{18} \mathrm{~F}$-L-FEHTP and ${ }^{18} \mathrm{~F}$-FDOPA ( $P>0.05 ;{ }^{18} \mathrm{~F}$-FDOPA after $S$-carbidopa pretreatment). There were significant differences between ${ }^{18} \mathrm{~F}$-DOPA SUVs with and without $S$-carbidopa pretreatment $(P<0.01)$ but not between the xenograftto-reference tissue SUV ratios with and without $S$-carbidopa pretreatment. Note that MDA-MB-231 tumors had gelatinous core. 
and xenograft-to-reference tissue SUV ratios were lower by trend but without significance $(P>0.05)$. The SUV ratios for NCI-H69 xenografts were $1.71 \pm 0.26$ (with L-tryptophan preadministration, $n=4$ ) versus $1.95 \pm 0.30$ (no L-tryptophan preadministration, $n=3$, from Fig. 7C) and for PC-3 xenografts $1.57 \pm 0.05$ (with L-tryptophan preadministration, $n=4$ ) versus $1.80 \pm 0.39$ (no L-tryptophan preadministration, $n=7$, from Fig. 7C).

\section{Influence of AADC Inhibition on ${ }^{18}$ F-FDOPA PET}

The ${ }^{18}$ F-FDOPA PET scans shown in Figure 7A were performed after $S$-carbidopa pretreatment. Four PC-3 xenograftbearing BALB/c mice were also scanned with ${ }^{18} \mathrm{~F}$-FDOPA in the absence of $S$-carbidopa. The ${ }^{18}$ F-FDOPA SUVs in the xenografts and reference tissues were about $50 \%$ those after $S$-carbidopa pretreatment (Fig. 7B). However, the average xenograft-to-reference tissue SUV ratios in the 2 protocols were not significantly different (Fig. 7C). The xenograft and background ${ }^{18}$ F-L-FEHTP SUVs in the same mice were not significantly different from those in the NMRI nude mice (Fig. 7B). The ${ }^{18} \mathrm{~F}-\mathrm{L}-\mathrm{FEHTP}$ xenograft-to-reference tissue SUV ratio in the PC-3 xenograft-bearing BALB/c mice was $2.1 \pm 0.3(n=4) . S$-carbidopa had no influence on ${ }^{18} \mathrm{~F}-\mathrm{L}-$ FEHTP PET images (Supplemental Material).

\section{Ex Vivo Biodistribution and In Vitro Serum Albumin Binding}

Table 1 shows average uptake values (SUV) for ${ }^{18} \mathrm{~F}-\mathrm{L}-$ FEHTP 70 min after injection. The levels of uptake (reported as percentage injected dose per gram of body weight [\% ID/ g]) were highest in the pancreas $(29-55 \% \mathrm{ID} / \mathrm{g})$ and then the kidneys (6-18\% ID/g) and xenografts (5-9 \% ID/g). The preadministration of tryptophan at $25 \mathrm{mg} / \mathrm{kg}$ had no significant influence on the biodistribution of ${ }^{18} \mathrm{~F}-\mathrm{L}$-FEHTP but resulted in a generally lower level of uptake in tissues with high LAT1 expression, that is, NCI-H69 xenografts, brain, and kidneys.

A high level of plasma protein binding could result in a high level of background radioactivity because of slow clearance from the blood. Plasma tryptophan is associated to $80 \%-90 \%$ with albumin (20). The bound fraction of ${ }^{18} \mathrm{~F}-\mathrm{L}-\mathrm{FEHTP}$ in $4 \%$ bovine serum albumin at $37^{\circ} \mathrm{C}$ was negligible, that is, $0.05 \pm$ 0.01 ( $n=4$ dialysis cells). No binding was detected with human or rat plasma diluted 1/20 (data not shown).

\section{DISCUSSION}

${ }^{18} \mathrm{~F}-\mathrm{L}-\mathrm{FEHTP}$ synthesis was similar to the procedure recently described by Li et al. (7), with similar radiochemical yield and purity. The complete radiolabeling process was established in a fully automated module, resulting in reproducible quality of the product and reducing the radioactivity burden on the radiochemist. The crude product was purified by semipreparative HPLC with $35 \mathrm{mM}$ acetate buffer containing $8 \%$ ethanol. The collected HPLC fraction was directly used for in vitro and in vivo experiments after neutralization with $8.4 \%$ sodium bicarbonate.

${ }^{18} \mathrm{~F}$-L-FEHTP accumulated in cancer cells of endocrine, pseudoendocrine, and exocrine phenotypes in vitro and in vivo. Decarboxylation or another metabolic step was not involved in the accumulation, confirming that increased transport alone is sufficient for tumor imaging by PET with labeled large neutral amino acids (2).

Because ${ }^{18} \mathrm{~F}$-L-FEHTP uptake into the cells was observed not only at $37^{\circ} \mathrm{C}$ but also at $4^{\circ} \mathrm{C}$ and because efflux was accelerated by the addition of L-leucine, we concluded that accumulation was mediated by the exchange of one or more

TABLE 1

Ex Vivo Biodistribution* Data for ${ }^{18} \mathrm{~F}-\mathrm{L}-\mathrm{FEHTP} 70$ Minutes After Injection

\begin{tabular}{|c|c|c|c|}
\hline \multirow[b]{2}{*}{ Tissue } & \multicolumn{3}{|c|}{${ }^{18} \mathrm{~F}-\mathrm{L}-\mathrm{FEHTP}$ biodistribution (SUV) in: } \\
\hline & $\begin{array}{l}\mathrm{NCl}-\mathrm{H} 69 \text { xenograft-bearing } \\
\text { mice }(n=3)\end{array}$ & $\begin{array}{c}\mathrm{NCl}-\mathrm{H} 69 \text { xenograft-bearing } \\
\text { mice given tryptophan at } 25 \mathrm{mg} / \mathrm{kg}(n=3)\end{array}$ & $\begin{array}{l}\text { PC-3 xenograft-bearing } \\
\text { mice }(n=4)\end{array}$ \\
\hline Xenograft & $1.58 \pm 0.48$ & $1.24 \pm 0.21$ & $1.40 \pm 0.35$ \\
\hline Adrenal glands & $0.74 \pm 0.14$ & $1.00 \pm 0.50$ & $0.87 \pm 0.22$ \\
\hline Blood & $0.75 \pm 0.08$ & $0.79 \pm 0.05$ & $0.77 \pm 0.08$ \\
\hline Brain & $0.84 \pm 0.32$ & $0.67 \pm 0.05$ & $0.68 \pm 0.06$ \\
\hline Gallbladder & $0.79 \pm 0.15$ & $1.04 \pm 0.67$ & $1.06 \pm 0.43$ \\
\hline Heart & $0.78 \pm 0.11$ & $0.79 \pm 0.05$ & $0.78 \pm 0.07$ \\
\hline Intestines with contents & $0.78 \pm 0.33$ & $0.84 \pm 0.07$ & $0.64 \pm 0.06$ \\
\hline Kidneys & $2.05 \pm 0.59$ & $1.73 \pm 0.14$ & $2.00 \pm 0.69$ \\
\hline Liver & $0.81 \pm 0.10$ & $0.83 \pm 0.05$ & $0.85 \pm 0.15$ \\
\hline Lungs & $0.73 \pm 0.13$ & $0.78 \pm 0.03$ & $0.74 \pm 0.12$ \\
\hline Pancreas & $8.50 \pm 1.64$ & $8.06 \pm 0.32$ & $8.15 \pm 1.32$ \\
\hline Spleen & $0.88 \pm 0.20$ & $0.82 \pm 0.09$ & $0.83 \pm 0.08$ \\
\hline Salivary glands & $0.77 \pm 0.15$ & $0.81 \pm 0.05$ & $0.74 \pm 0.07$ \\
\hline Urine (range) & $27-111$ & 54-110 & $29-72$ \\
\hline
\end{tabular}

\footnotetext{
${ }^{*}$ Accumulated radioactivity per gram of tissue divided by radioactivity dose per gram of body weight (SUV). Data are reported as average \pm SD unless otherwise indicated.

See Ishiwata et al. (41) for ${ }^{18} \mathrm{~F}-\mathrm{FDOPA}$ tissue distribution.
} 
amino acids rather than unilateral or concentrative transporters. The low temperature sensitivity of the cell uptake of ${ }^{18} \mathrm{~F}$-L-FEHTP was in line with the results of an early study on L-tryptophan uptake into Ehrlich ascites tumor cells (21). Exchange transporters carrying neutral aromatic amino acids are SLC7A5 (LAT1), SLC7A6 (Y+LAT2), SLC7A7 (Y+LAT1), SLC7A8 (LAT2), SLC7A9 $(B(0,+)$ AT), SLC43A1 (LAT3), and SLC43A2 (LAT4) $(14,22)$. $\mathrm{Na}^{+}$-dependent symporters that may also be involved in the transport of L-tryptophan analogs are SLC1A5 (ATB0, ASCT2) and SLC6A14 (ATB0+) (14).

The cell uptake of ${ }^{18} \mathrm{~F}-\mathrm{L}-\mathrm{FEHTP}$ was inhibited to greater than $95 \%$ by $10 \mathrm{mM} \mathrm{BCH}$ in all tested cell lines. $\mathrm{BCH}$ is a substrate and competitive inhibitor of $\mathrm{Na}^{+}$-independent transport of large neutral amino acids, with typical transporter-inhibitor constants $\mathrm{K}_{\mathrm{i}}$ values of less than $1 \mathrm{mM}$ for SLC7A5 (LAT1) and SLC7A8 (LAT2) (23,24). SLC7A6, SLC7A7, SLC1A5, and SLC6A14 were not directly inhibited by $\mathrm{BCH}$, and no amino acid efflux was observed for SLC7A7 after the addition of L-leucine (25-29). SLC7A9, SLC43A1, and SLC43A2 were only moderately inhibited by $10 \mathrm{mM}$ BCH (30-32).

Considering the highly efficient transport inhibition by 10 $\mathrm{mM} \mathrm{BCH}$ in our experiments with 3 tumor cell lines of different phenotypes, we concluded that ${ }^{18} \mathrm{~F}$-L-FEHTP was almost exclusively taken up by LAT1 or LAT2. The latter is, however, not typically overexpressed in cancer cells (33). ${ }^{18} \mathrm{~F}-\mathrm{FDOPA}$ influx into MDA-MB-231 nonendocrine cells was almost completely blocked by $\mathrm{BCH}$, also suggesting LAT1 or LAT2 as the major uptake mechanism. These results were in agreement with the findings of Neels et al. (5).

${ }^{18} \mathrm{~F}$-FDOPA radioactivity was released from NCI-H69 endocrine cells during uptake experiments at $37^{\circ} \mathrm{C}$ but not at $4{ }^{\circ} \mathrm{C}$, suggesting an energy-driven mechanism. According to the APUD concept, a higher level of accumulation of ${ }^{18} \mathrm{~F}-\mathrm{FDOPA}$ radioactivity would be expected at $37^{\circ} \mathrm{C}$ than at $4^{\circ} \mathrm{C}$ because of accumulation via enzymatic decarboxylation. The unexpected energy-dependent efflux of radioactivity was inhibited by the AADC inhibitor $S$-carbidopa, indicating that it was related to ${ }^{18}$ F-FDOPA decarboxylation. The observed AADC-dependent efflux may have resulted from the release of the decarboxylation product $6-{ }^{18} \mathrm{~F}$-fluoro-L-dopamine. In contrast to the ${ }^{18} \mathrm{~F}$-FDOPA results, the kinetics and extent of ${ }^{18} \mathrm{~F}$-L-FEHTP uptake were temperature independent, excluding the involvement of any energy-dependent mechanism, such as AADC.

${ }^{18} \mathrm{~F}$-L-FEHTP and ${ }^{18} \mathrm{~F}$-FDOPA accumulated significantly in NCI-H69 and PC-3 xenografts, with no significant difference between the tracers or the tumor models at scan times between 30 and $45 \mathrm{~min}$ after injection. MDA-MB-231 xenografts were not ideal for quantitative comparisons because of their large gelatinous core. However, both tracers accumulated in the intact periphery of the xenografts.

Our data indicated that ${ }^{18} \mathrm{~F}$-L-FEHTP was not decarboxylated in vivo. In contrast to the findings obtained with ${ }^{18}$ F-FDOPA, the AADC inhibitor $S$-carbidopa had no influence on ${ }^{18} \mathrm{~F}$-L-FEHTP PET images. Furthermore, no metabolites of L-FEHTP were detected in tumor homogenates, and only traces of metabolites were found in blood. Although the ${ }^{18} \mathrm{~F}$-FDOPA SUV ratios for PC-3 xenografts and reference tissues did not decrease between 30 and $150 \mathrm{~min}$, in line with the APUD concept, the respective SUV ratios of ${ }^{18} \mathrm{~F}$-L-FEHTP decreased with time. The observed metabolic stability of ${ }^{18} \mathrm{~F}-\mathrm{L}-\mathrm{FEHTP}$ was in contrast to the findings obtained with ${ }^{11} \mathrm{C}-5 \mathrm{HTP}(5,19)$. The latter was almost quantitatively decarboxylated within minutes in human carcinoid (endocrine) liver tumors and metastases (19).

The methylation of L-3,4-dihydroxyphenylalanine at catechol 3-OH resulted in the loss of its properties as a substrate or inhibitor of AADC, suggesting that binding to the active site was abolished (34). On the basis of these findings and our observations with ${ }^{18} \mathrm{~F}-\mathrm{L}-\mathrm{FEHTP}$, it may be speculated that $O$-alkylation in the aromatic system of AADC substrates changes their electronic or steric properties in a way that disfavors binding to the active site. Structureactivity relationship, site-directed mutagenesis, or molecular modeling studies are required to elaborate the structural properties of AADC substrates.

Our findings indicated that the mechanism of ${ }^{18} \mathrm{~F}$-L-FEHTP accumulation was more similar to that of ${ }^{18} \mathrm{~F}$-FET than to that of ${ }^{11} \mathrm{C}-5 \mathrm{HTP} .{ }^{18} \mathrm{~F}-\mathrm{FET}$ is taken up by transport systems but is not metabolized in tumor cells (2). In mice with peripheral xenografts, ${ }^{18}$ F-L-FEHTP and ${ }^{18}$ F-FET showed similar distribution and kinetic behaviors, including brain uptake, with higher relative kidney radioactivity of ${ }^{18} \mathrm{~F}-\mathrm{L}-\mathrm{FEHTP}$ than of ${ }^{18} \mathrm{~F}$-FET (35). In vitro ${ }^{18} \mathrm{~F}$-FET uptake was less efficiently inhibited by BCH than we observed for ${ }^{18} \mathrm{~F}$-L-FEHTP (2), indicating that the latter may be more selective for LAT1 than ${ }^{18}$ F-FET. However, only a direct comparison will provide a definitive conclusion.

L-tryptophan is a substrate of indoleamine 2,3-dioxygenase (IDO). Intracellular IDO activity may result in the trapping of polar ${ }^{18} \mathrm{~F}$-L-FEHTP metabolites or in indirect ${ }^{18} \mathrm{~F}$-L-FEHTP accumulation via intracellular L-tryptophan depletion. Significant IDO activity was shown for MDA-MB-231 cells after interferon- $\gamma$ stimulation (12). We did not detect any radiometabolites in MDA-MB-231 xenografts 15 min after injection and therefore did not further investigate this potential route of ${ }^{18} \mathrm{~F}$-L-FEHTP radioactivity accumulation.

In view of the evaluation of LAT1 substrates and inhibitors as potential anticancer drugs (36-38), ${ }^{18} \mathrm{~F}$-L-FEHTP is a candidate PET tracer for staging tumors according to their LAT1 expression and activity and therefore their susceptibility to LAT1-targeted drugs. In addition, the in vivo efficiency of LAT1 inhibitors may be monitored directly by PET. Further studies are required to show the correlation between tumor LAT1 activity and ${ }^{18} \mathrm{~F}$-L-FEHTP uptake kinetics in vitro and in vivo and to evaluate the direct and indirect effects of other amino acid transporters and IDO on this correlation.

We found relatively high levels of ${ }^{18} \mathrm{~F}-\mathrm{L}-\mathrm{FEHTP}$ and ${ }^{18} \mathrm{~F}-\mathrm{FDOPA}$ radioactivity in all tissues, with notably high activity in the pancreas. Serum albumin binding was excluded as a cause of high levels of ${ }^{18} \mathrm{~F}$-L-FEHTP back- 
ground activity. The latter may be assigned to the relatively high LAT1 expression in healthy rodent tissue. Mice have relatively high LAT1 expression levels in most tissues, with particularly high levels in the pancreas. Humans have high LAT1 expression levels in protective endothelial and epithelial barriers and in proliferating cells but negligible expression in other tissues $(22,25,39,40)$. Taking these species differences into account, we expect lower levels of background radioactivity in humans and therefore higher SUV ratios between tumors with increased LAT1 activity and healthy tissues.

\section{CONCLUSION}

We have characterized the biochemical and pharmacologic properties of ${ }^{18} \mathrm{~F}$-L-FEHTP, an ${ }^{18} \mathrm{~F}$-labeled aromatic L-amino acid analog with promise for tumor imaging. We identified ${ }^{18} \mathrm{~F}$-L-FEHTP as a substrate for LAT $1 / 2$ transport but not for decarboxylation by AADC. Therefore, ${ }^{18}$ F-L-FEHTP is a potent PET probe for the LAT1 activity of malignant lesions, independent of the AADC activity of tumors and healthy tissues. It may be used in the future to stage tumors for susceptibility to LAT1-targeted drugs.

\section{DISCLOSURE STATEMENT}

The costs of publication of this article were defrayed in part by the payment of page charges. Therefore, and solely to indicate this fact, this article is hereby marked "advertisement" in accordance with 18 USC section 1734.

\section{ACKNOWLEDGMENTS}

We thank Petra Wirth for assistance with animal experiments and Bruno Mancosu, Judith Frässdorf, Anass Johayem, and Zoran Vujicic for assistance with tracer development and for tracer production. We thank Olga S. Fedorova and Holger Siebeneicher for their contributions to tracer development. We thank Sandra Borkowski, Sabine Zitzmann-Kolbe, Keith Graham, and Ludger Dinkelborg from Bayer Schering Pharma for fruitful discussions. No potential conflict of interest relevant to this article was reported.

\section{REFERENCES}

1. Plathow C, Weber WA. Tumor cell metabolism imaging. J Nucl Med. 2008;49 (suppl):43S-63S.

2. Langen KJ, Hamacher $\mathrm{K}$, Weckesser $\mathrm{M}$, et al. $O$ - $\left(2-\left[{ }^{18} \mathrm{~F}\right]\right.$ fluoroethyl $)-\mathrm{L}-$ tyrosine: uptake mechanisms and clinical applications. Nucl Med Biol. 2006;33:287-294.

3. Sundin A, Eriksson B, Bergstrom M, et al. PET in the diagnosis of neuroendocrine tumors. Ann N Y Acad Sci. 2004;1014:246-257.

4. Pearse AG. The APUD concept and hormone production. Clin Endocrinol Metab. 1980;9:211-222.

5. Neels OC, Koopmans KP, Jager PL, et al. Manipulation of $\left[{ }^{11} \mathrm{C}\right]-5$-hydroxytryptophan and 6- $\left[{ }^{18} \mathrm{~F}\right]$ fluoro-3,4-dihydroxy-L-phenylalanine accumulation in neuroendocrine tumor cells. Cancer Res. 2008;68:7183-7190.

6. Ametamey SM, Honer M, Schubiger PA. Molecular imaging with PET. Chem Rev. 2008;108:1501-1516.

7. Li R, Wu SC, Wang SC, et al. Synthesis and evaluation of L-5- $\left(2-\left[{ }^{18} \mathrm{~F}\right]\right.$ fluoroethoxy $)$ tryptophan as a new PET tracer. Appl Radiat Isot. 2010;68:303-308.

8. Carney DN, Gazdar AF, Bepler G, et al. Establishment and identification of small cell lung-cancer cell-lines having classic and variant features. Cancer Res. 1985;45:29132923.
9. Avgeris M, Koutalellis G, Fragoulis EG, Scorilas A. Expression analysis and clinical utility of L-Dopa decarboxylase (DDC) in prostate cancer. Clin Biochem. 2008;41:1140-1149.

10. Oka S, Okudaira H, Yoshida Y, et al. Transport mechanisms of trans-1-amino-3fluoro[1-14C $]$ cyclobutanecarboxylic acid in prostate cancer cells. Nucl Med Biol. 2012;39:109-119.

11. Miko E, Margitai Z, Czimmerer Z, et al. miR-126 inhibits proliferation of small cell lung cancer cells by targeting SLC7A5. FEBS Lett. 2011;585:1191-1196.

12. Travers MT, Gow IF, Barber MC, et al. Indoleamine 2,3-dioxygenase activity and L-tryptophan transport in human breast cancer cells. Biochim Biophys Acta. 2004;1661:106-112.

13. Namavari M, Bishop A, Satyamurthy $\mathrm{N}$, et al. Regioselective radiofluorodestannylation with $\left[{ }^{18} \mathrm{~F}\right] \mathrm{F}_{2}$ and $\left[{ }^{18} \mathrm{~F}\right] \mathrm{CH}_{3} \mathrm{COOF}$ : a high yield synthesis of $6-\left[{ }^{18} \mathrm{~F}\right]$ fluoro-L-dopa. Int J Rad Appl Instrum A. 1992;43:989-996.

14. UniProt Consortium. UniProt Web site. Available at: www.uniprot.org. Accessed January 19,2012

15. Honer $\mathrm{M}$, Brühlmeier $\mathrm{M}$, Missimer $\mathrm{J}$, et al. Dynamic imaging of striatal $\mathrm{D}_{2}$ receptors in mice using quad-HIDAC PET. J Nucl Med. 2004;45:464-470.

16. Wang Y, Seidel J, Tsui BM, et al. Performance evaluation of the GE Healthcare eXplore VISTA dual-ring small-animal PET scanner. J Nucl Med. 2006;47:1891-1900.

17. Verbeek MM, Geurtz PB, Willemsen MA, Wevers RA. Aromatic L-amino acid decarboxylase enzyme activity in deficient patients and heterozygotes. Mol Genet Metab. 2007;90:363-369.

18. Gilbert JA, Frederick LM, Ames MM. The aromatic-L-amino acid decarboxylase inhibitor carbidopa is selectively cytotoxic to human pulmonary carcinoid and small cell lung carcinoma cells. Clin Cancer Res. 2000;6:4365-4372.

19. Sundin A, Eriksson B, Bergström M, et al. Demonstration of $\left[{ }^{11} \mathrm{C}\right]$ 5-hydroxy-Ltryptophan uptake and decarboxylation in carcinoid tumors by specific positioning labeling in positron emission tomography. Nucl Med Biol. 2000;27:33-41.

20. Yuwiler A, Oldendorf WH, Geller E, Braun L. Effect of albumin binding and amino acid competition on tryptophan uptake into brain. J Neurochem. 1977;28:1015-1023.

21. Jacquez JA, Sherman JH, Terris J. Temperature dependence of amino acid transport in Ehrlich ascites cells: with results which bear on the A-L distinction. Biochim Biophys Acta. 1970;203:150-166.

22. Verrey F. System L: heteromeric exchangers of large, neutral amino acids involved in directional transport. Pflugers Arch. 2003;445:529-533.

23. Stevens BR, Ross HJ, Wright EM. Multiple transport pathways for neutral amino acids in rabbit jejunal brush-border vesicles. J Membr Biol. 1982;66:213-225.

24. Kudo Y, Boyd CA. Characterisation of L-tryptophan transporters in human placenta: a comparison of brush border and basal membrane vesicles. J Physiol. 2001;531:405416.

25. Bröer A, Wagner CA, Lang F, Broer S. The heterodimeric amino acid transporter $4 \mathrm{~F} 2 \mathrm{hc} / \mathrm{y}+\mathrm{LAT} 2$ mediates arginine efflux in exchange with glutamine. Biochem J. 2000;349:787-795.

26. Pfeiffer R, Rossier G, Spindler B, et al. Amino acid transport of $y+L$-type by heterodimers of $4 \mathrm{~F} 2 \mathrm{hc} / \mathrm{CD} 98$ and members of the glycoprotein-associated amino acid transporter family. EMBO J. 1999;18:49-57.

27. Kanai Y, Fukasawa $\mathrm{Y}$, Cha $\mathrm{SH}$, et al. Transport properties of a system $\mathrm{y}+\mathrm{L}$ neutral and basic amino acid transporter: insights into the mechanisms of substrate recognition. J Biol Chem. 2000;275:20787-20793.

28. Sloan JL, Mager S. Cloning and functional expression of a human $\mathrm{Na}^{+}$and $\mathrm{Cl}^{-}$-dependent neutral and cationic amino acid transporter $\mathrm{B}(0+)$. J Biol Chem. 1999;274:23740-23745.

29. Kirchhoff P, Dave MH, Remy C, et al. An amino acid transporter involved in gastric acid secretion. Pflugers Arch. 2006;451:738-748.

30. Taylor PM, Hundal HS, Rennie MJ. Transport of glutamine in Xenopus laevis oocytes: relationship with transport of other amino acids. J Membr Biol. 1989;112:149-157.

31. Babu E, Kanai Y, Chairoungdua A, et al. Identification of a novel system L amino acid transporter structurally distinct from heterodimeric amino acid transporters. J Biol Chem. 2003;278:43838-43845.

32. Bodoy S, Martin L, Zorzano A, et al. Identification of LAT4, a novel amino acid transporter with system L activity. J Biol Chem. 2005;280:12002-12011.

33. Haase C, Bergmann R, Fuechtner F, et al. L-type amino acid transporters LAT1 and LAT4 in cancer: uptake of 3-O-methyl-6- ${ }^{18} \mathrm{~F}$-fluoro-L-dopa in human adenocarcinoma and squamous cell carcinoma in vitro and in vivo. J Nucl Med. 2007;48:20632071.

34. Soares-da-Silva P, Parada A, Serrao P. The $O$-methylated derivative of L-DOPA, 3$O$-methyl-L-DOPA, fails to inhibit neuronal and non-neuronal aromatic L-amino acid decarboxylase. Brain Res. 2000;863:293-297.

35. Wester HJ, Herz M, Weber W, et al. Synthesis and radiopharmacology of $O-\left(2-\left[{ }^{18} \mathrm{~F}\right]\right.$ fluoroethyl)-L-tyrosine for tumor imaging. J Nucl Med. 1999;40:205-212.

36. Imai H, Kaira $\mathrm{K}$, Oriuchi $\mathrm{N}$, et al. Inhibition of L-type amino acid transporter 1 has antitumor activity in non-small cell lung cancer. Anticancer Res. 2010;30:4819-4828. 
37. Fan X, Ross DD, Arakawa $\mathrm{H}$, et al. Impact of system $\mathrm{L}$ amino acid transporter 1 (LAT1) on proliferation of human ovarian cancer cells: a possible target for combination therapy with anti-proliferative aminopeptidase inhibitors. Biochem Pharmacol. 2010;80:811-818.

38. Lin J, Raoof DA, Thomas DG, et al. L-type amino acid transporter-1 overexpression and melphalan sensitivity in Barrett's adenocarcinoma. Neoplasia. 2004;6: 74-84.
39. Heiss P, Mayer S, Herz M, et al. Investigation of transport mechanism and uptake kinetics of $\mathrm{O}$-(2-[ $\left[{ }^{18} \mathrm{~F}\right]$ fluoroethyl)-L-tyrosine in vitro and in vivo. $\mathrm{J} \mathrm{Nucl} \mathrm{Med}$. 1999;40:1367-1373.

40. Blomquist L. Species differences in the accumulation of 4-iodophenylalanine in the exocrine pancreas. Comp Biochem Physiol. 1969;28:777-782.

41. Ishiwata K, Kubota K, Kubota R, et al. Selective 2-[ $\left.{ }^{18} \mathrm{~F}\right]$ fluorodopa uptake for melanogenesis in murine metastatic melanomas. J Nucl Med. 1991;32:95-101. 